\title{
Modelling Simultaneous Alloy Carbide Sequence in Power Plant Steels
}

\author{
Nobuhiro FUJITA and H. K. D. H. BHADESHIA ${ }^{1)}$ \\ Steel Research Laboratories, Nippon Steel Corporation, Shintomi, Futtsu 293-8511 Japan. \\ 1) Department of Materials Science and Metallurgy, University of Cambridge, Pembroke Street, Cambridge, CB2 $30 Z$, UK.
}

(Received on February 5, 2002; accepted in final form on March 18, 2002)

\begin{abstract}
A method has recently been developed to estimate the speed with which precipitation reactions occur in power plant steels. It is based on Avrami theory but with an adaptation that allows the treatment of simultaneous reactions. In the present work, a number of approximations and inconsistencies in the theory have been eliminated and this kinetic theory for simultaneous reactions has been modified with the treatments of both diffusion-controlled growth and capillarity effect in multicomponent systems. The modified model can predict not only volume fraction changes of each carbide but also particle sizes. New experimental results on alloy carbide in $3 \mathrm{Cr} 1.5 \mathrm{Mo}$ and $2 \frac{1}{4} \mathrm{Cr} 1 \mathrm{Mo}$ steels are reported and shown to be comparable to the modified theory.
\end{abstract}

KEY WORDS: modelling; precipitation; alloy carbide; power plant steel.

\section{Introduction}

Steels for use at elevated temperature rely on a variety of precipitates for their resistance to creep deformation. The precipitation process in the vast majority of creep-resistant steels occurs in a complicated manner, beginning with phases which are easy to nucleate but which are metastable. It is only after prolonged aging (e.g. many decades at $600^{\circ} \mathrm{C}$ ) that the equilibrium phase mixture might be obtained. This is just as well because the equilibrium microstructure is unlikely to be useful in creep applications.

Steels destined for power plant applications might contain any of the following precipitates: iron base carbides or carbonitrides $\left(\mathrm{M}_{3} \mathrm{C}, \mathrm{M}_{2.4} \mathrm{C}\right.$ etc. $), \mathrm{M}(\mathrm{C}, \mathrm{N}), \mathrm{M}_{2}(\mathrm{C}, \mathrm{N}), \mathrm{M}_{7} \mathrm{C}_{3}$, $\mathrm{M}_{23} \mathrm{C}_{6}, \mathrm{M}_{5} \mathrm{C}_{2}, \mathrm{M}_{6} \mathrm{C}$, graphite and Laves phase ( $\mathrm{M}$ stands for metallic solute atom). It is obviously difficult to design a steel with specific particles in mind given the complexity of the precipitation events. A theory has recently been proposed $^{1-3)}$ which adapts the classical Avrami ${ }^{4-8)}$ model to enable simultaneous precipitation reactions to be tackled. Although such work is of use in the design of new alloys, a number of fundamental problems which are outside of that framework of simultaneous transformations were pointed out, ${ }^{9,10)}$ associated with the growth of individual phases. In the present work, the theory has been modified to obtain accurate solutions:

- Consumption of Nucleation Sites

In previous work, ${ }^{1,2,9,10)}$ the nucleation rate has been calculated with the following equation, $I=N_{0}(k T / h) \exp \left\{-\left(G^{*}\right.\right.$ $+Q) / k T\}$. As suggested by Turnbull and Fisher, ${ }^{11)}$ when there is solute diffusion during nucleation, the equation is multiplied by the mole fraction of solute with $Q$ being the activation energy for the diffusion of solute. When this equation is incorporated into the Avrami overall transformation kinetics theory, an additional term $\left(1-V^{\prime} / V^{\text {eq }}\right)$ appears to allow for the fraction of the matrix which is eliminated from the transformation process as the reaction proceeds. The term accounts for the consumption of nucleation sites:

$$
I^{\prime}=\bar{c}\left(1-\frac{V^{\prime}}{V^{\mathrm{eq}}}\right) N_{0} \frac{k T}{h} \exp \left(-\frac{G^{*}+Q}{k T}\right)
$$

where $V^{\prime}$ and $V^{\text {eq }}$ are volume fraction at any instance and equilibrium volume fraction for a precipitate respectively.

\section{- Multicomponent Diffusion}

For the growth of precipitation of alloy carbides in steels, local equilibrium at the interface is a reasonable approximation for isothermal diffusion-controlled growth. It follows that for a binary alloy these compositions are given by a tie-line of the equilibrium phase diagram.

Solute is removed from the matrix as the precipitate grows but since the temperature is fixed during isothermal transformation, the interface compositions must remain fixed at $c^{\alpha \beta}$ and $c^{\beta \alpha}$, which are equilibrium concentrations in matrix $\alpha$ and precipitate $\beta$ respectively, if local equilibrium is to be maintained. It follows that the rate at which solute is removed from the matrix as the precipitate grows must be equal to the flux of solute to the $\alpha / \beta$ interface:

$$
v\left(c^{\beta \alpha}-c^{\alpha \beta}\right)=-\left.D \frac{\partial c}{\partial z}\right|_{z=z^{*}}
$$

where $c$ is concentration, $v$ is the interfacial velocity, $z$ is 
the axis along the growth direction, $z^{*}$ is the position of the interface and $D$ is the solute diffusion coefficient in the matrix phase. The concentration gradient is evaluated at the position of the interface.

However, alloy carbide formation in practical steels involves the diffusion of both substitutional and interstitial solutes. Therefore, the binary $\mathrm{Fe}-\mathrm{M}$ treatment as used in previous work ${ }^{1,2}$ is inadequate for alloy carbide formation in practical steels, because the mass balance equation will not be satisfied for the interstitial solute. In general, it should be very complex to satisfy all mass conservation equations for each solute simultaneously. A ternary system, in which alloy carbide formation involved with both metallic solute $\mathrm{M}$ and carbon $\mathrm{C}$, is the simplest approximation for alloy carbide formation in practical steels. There are two such equations for both carbon $\mathrm{C}$ and substitutional solute $\mathrm{M}$ which have to be satisfied ${ }^{\dagger}$ :

$$
\begin{aligned}
& v\left(c_{\mathrm{M}}^{\beta \alpha}-c_{\mathrm{M}}^{\alpha \beta}\right)=-\left.D_{\mathrm{M}} \frac{\partial c_{\mathrm{M}}}{\partial z}\right|_{z=z^{*}} \\
& v\left(c_{\mathrm{C}}^{\beta \alpha}-c_{\mathrm{C}}^{\alpha \beta}\right)=-\left.D_{\mathrm{C}} \frac{\partial c_{\mathrm{C}}}{\partial z}\right|_{z=z^{*}}
\end{aligned}
$$

Because $D_{\mathrm{M}} \ll D_{\mathrm{C}}$, it would in general be impossible to satisfy these equations simultaneously for a tie-line passing through alloy composition $\bar{c}$. However, for a ternary alloy, there is an additional degree of freedom given by the phase rule so that there is a choice of tie-lines at any given temperature. The local equilibrium condition can be maintained by choosing a tie-line which either minimises the concentration gradient of carbon (thus allowing substitutional solute flux to keep pace) or maximises the gradient of the substitutional solute to compensate for its small diffusivity.

These concepts are well established in treatments of the growth of ferrite from austenite and the formation of austenite and dissolution of cementite, ${ }^{14)}$ but as a first approximation were not incorporated in the calculations of carbide precipitation kinetics ${ }^{1,2)}$ where the diffusion-controlled growth was treated essentially as a binary $\mathrm{Fe}-\mathrm{M}$ problem.

\section{- Capillarity}

The state of equilibrium between two phases changes with the curvature of the interface separating them. This well-established capillarity effect scales with the interfacial energy because additional work has to be done to create new interfacial area as a curved interface moves. The free energy of a carbide phase varies relatively sharply with deviations from the stoichiometric composition so it can be assumed that the carbide composition is not sensitive to the interface curvature. However, the equilibrium composition of matrix changes as follows ${ }^{15}$ :

$$
c_{\mathrm{r}}^{\alpha \beta}=\left(1+\frac{2 \Gamma}{r}\right) c^{\alpha \beta} \quad \text { with } \quad \Gamma=\frac{\sigma v^{\beta}}{k T} \frac{1-c^{\alpha \beta}}{c^{\beta \alpha}-c^{\alpha \beta}}
$$

where $r$ is the radius of curvature at the tip, $\Gamma$ is a capillarity coefficient which is directly proportional to the interfacial energy $\sigma$ and $c^{\alpha \beta}$ is the solute concentration in matrix $\alpha$ which is in equilibrium with carbide $(\beta)$ when $r=\infty . v^{\beta}$ is the molar volume of the $\beta$ phase. The modified composition $c_{\mathrm{r}}^{\alpha \beta}$ is therefore easy to estimate for a binary alloy. At some critical value of $r=r_{\mathrm{c}}, c_{\mathrm{r}}^{\alpha \beta}=\bar{c}$ and growth ceases.

Equation (4) cannot simply be applied to a ternary alloy with two solutes, bearing in mind that the concentrations for carbon $\mathrm{C}$ and substitutional solute $\mathrm{M}$ in the matrix $\alpha$ at the interface, $c_{\mathrm{C}}^{\alpha \beta}$ and $c_{\mathrm{M}}^{\alpha \beta}$, are not independent but are connected by a tie-line of the phase diagram. A straightforward application to each solute in turn simply gives two different values of $r{ }^{16)}$ a situation of which is not physical since there is only one interface for both solutes. The problem of multicomponent capillarity within the constraint of local equilibrium has been solved.

\section{- Summary}

Previous work ${ }^{1,2)}$ on the calculations of the kinetics of precipitation reactions in power plant steels has been based on carbide growth in binary $\mathrm{Fe}-\mathrm{M}$ systems. This was justified by stating that since carbon diffuses rapidly, growth should be controlled by the slower diffusing $\mathrm{M}$ atom. We now know that this is not a reasonable approximation because it fails to ensure mass balance for all other species of atoms involved in the transformation. The binary approximation is also inappropriate for capillarity effect because it leads to different tip radii for different solutes.

The aim of this work is to resolve these difficulties and to test the new methodology for alloy carbide sequence in two typical power plant steels, $2 \frac{1}{4} \mathrm{Cr} 1 \mathrm{Mo}$ and $3 \mathrm{Cr} 1.5 \mathrm{Mo} \mathrm{wt} \%$ steels after cementite in isothermal heat treatment.

\section{Experimental Procedure}

Table 1 shows the chemical compositions of the alloys used. These steels were vacuum-melted as $15 \mathrm{~kg}$ ingots, heated at $1250^{\circ} \mathrm{C}$ for $30 \mathrm{~min}$ in an argon atmosphere, hotrolled to $15 \mathrm{~mm}$ thickness plate and quenched from a finishing temperature of about $900^{\circ} \mathrm{C}$. From the plates, $3 \mathrm{~mm}$ and $8 \mathrm{~mm}$ diameter cylindrical specimens were machined for heat treatment. The specimens were sealed in silica tubes under a partial pressure of argon (about $150 \mathrm{~mm} \mathrm{Hg}$ ), before the homogenisation heat treatment. Using the thermodynamic software named MTDATA from the National Physical Laboratory ${ }^{17)}$ the equilibrium phases for each steel were calculated. According to these results, both steels became fully austenite at temperatures above $1200^{\circ} \mathrm{C}$. Therefore, the homogenisation temperature was chosen to be $1250^{\circ} \mathrm{C}$ where the samples were held for 3 days.

After the homogenisation treatment, the specimens were quenched into water with breaking silica tube. Then, specimens were sealed again and tempered at the expected service temperatures, $600^{\circ} \mathrm{C}, 650^{\circ} \mathrm{C}$ and $700^{\circ} \mathrm{C}$ for a maxi-

Table 1. Concentrations in $\mathrm{wt} \%$ of the major alloying elements in $2 \frac{1}{4} \mathrm{Cr} 1 \mathrm{Mo}$ and $3 \mathrm{Cr} 1.5 \mathrm{Mo}$ steels.

\begin{tabular}{|c|cccccc|}
\hline Steel & C & Si & Mn & Cr & Mo & N \\
\hline $2 \frac{1}{4}$ Cr1Mo & 0.15 & - & 0.49 & 2.16 & 0.92 & $\leq 0.005$ \\
\hline $3 \mathrm{Cr} 1.5 \mathrm{Mo}$ & 0.10 & - & 0.98 & 2.98 & 1.50 & $\leq 0.005$ \\
\hline
\end{tabular}

\footnotetext{
${ }^{\dagger}$ The equations presented here neglect cross-diffusion effects, e.g. the dependence of the flux of carbon on the gradient of M (Coates, 1973, ${ }^{12)}$; Kirkaldy,
} $\left.1958,{ }^{13}\right)$. This is considered to be a reasonable approximation in the present context due to the large differences in atomic mobilities. 
mum of $1000 \mathrm{~h}$. After tempering, all specimens were again quenched into water with breaking the tubes.

Electrolytically extracted residues of the specimens tempered at $600^{\circ} \mathrm{C}$ were analysed for the investigation of the precipitation sequence using X-rays.

The sizes of each alloy carbide were investigated using transmission electron microscopy (TEM) with carbon replicas. The lengths of needle-shaped particle (i.e.; $\mathrm{M}_{2} \mathrm{C}$ in this case) and the radii of spherical particles (i.e.; $\mathrm{M}_{7} \mathrm{C}_{3}$ and $\mathrm{M}_{23} \mathrm{C}_{6}$ in this case) were directly measured with TEM micrograph of the replicas. The particle sizes were measured with at least 100 particles for needle-shaped carbide $\left(\mathrm{M}_{2} \mathrm{C}\right)$ and 20 particles for spherical carbides $\left(\mathrm{M}_{7} \mathrm{C}_{3}\right.$ and $\left.\mathrm{M}_{23} \mathrm{C}_{6}\right)$ in each case. Because each alloy carbide precipitates at a different rate, the specific conditions of the samples used for the measurements are described in Table 2.

\section{Experimental Results}

\subsection{X-ray Analysis}

Table 3 shows a summary of the $\mathrm{X}$-ray analysis results of electrolytically extracted residues from $2 \frac{1}{4} \mathrm{Cr} 1 \mathrm{Mo}$ and $3 \mathrm{Cr} 1.5 \mathrm{Mo}$ steels tempered at $600^{\circ} \mathrm{C}$.

According to the X-ray data, there are differences in the carbide precipitation sequences between the $2 \frac{1}{4} \mathrm{Cr} 1 \mathrm{Mo}$ and $3 \mathrm{Cr} 1.5 \mathrm{Mo}$ steels. In the $2 \frac{1}{4} \mathrm{Cr} 1 \mathrm{Mo}$ steel, $\mathrm{M}_{2} \mathrm{C}$ can be detected earlier than $\mathrm{M}_{7} \mathrm{C}_{3}$, while in $3 \mathrm{Cr} 1.5 \mathrm{Mo}$ steel $\mathrm{M}_{2} \mathrm{C}$ follows the formation of $\mathrm{M}_{7} \mathrm{C}_{3}$. The X-ray intensity from $\mathrm{M}_{2} \mathrm{C}$

Table 2. Conditions of size measurements for each alloy carbide in $3 \mathrm{Cr} 1.5 \mathrm{Mo}$ and $2 \frac{1}{4} \mathrm{Cr} 1 \mathrm{Mo}$ steels.

\begin{tabular}{|c|c|c|}
\hline Type of carbide & steels & Measurement condition \\
\hline $\mathrm{M}_{2} \mathrm{C}$ & $2 \frac{1}{4} \mathrm{Cr} 1 \mathrm{Mo}$ & $600{ }^{\circ} \mathrm{C} \times 10,100$ and $1000 \mathrm{~h}$ \\
& & $650^{\circ} \mathrm{C} \times 10$ and $100 \mathrm{~h}$ \\
\hline $\mathrm{M}_{7} \mathrm{C}_{3}$ & $3 \mathrm{Cr} 1.5 \mathrm{Mo}$ & $600^{\circ} \mathrm{C} \times 10,100$ and $200 \mathrm{~h}$ \\
& & $650^{\circ} \mathrm{C} \times 10$ and $100 \mathrm{~h}$ \\
& $2 \frac{1}{4} \mathrm{Cr} 1 \mathrm{Mo}$ & $650^{\circ} \mathrm{C} \times 10$ and $100 \mathrm{~h}$ \\
\hline $\mathrm{M}_{23} \mathrm{C}_{6}$ & $3 \mathrm{Cr} 1.5 \mathrm{Mo}$ & $700^{\circ} \mathrm{C} \times 10$ and $100 \mathrm{~h}$ \\
\hline
\end{tabular}

Table 3. X-ray analysis results for residues extracted from $2 \frac{1}{4} \mathrm{Cr} 1 \mathrm{Mo}$ and $3 \mathrm{Cr} 1.5 \mathrm{Mo}$ steels tempered at $600^{\circ} \mathrm{C}$. The abbreviations, VS, S, W and VW mean very strong, strong, weak and very weak X-ray intensities, respectively.

\begin{tabular}{|c|c|c|c|c|c|}
\hline \multirow[t]{2}{*}{ Steels } & \multirow[t]{2}{*}{ Tempering condition } & \multicolumn{4}{|c|}{ Precipitates detected } \\
\hline & & $\mathrm{M}_{3} \mathrm{C}$ & $\mathrm{M}_{2} \mathrm{C}$ & $\mathrm{M}_{7} \mathrm{C}_{3}$ & $\mathrm{M}_{23} \mathrm{C}_{6}$ \\
\hline \multirow[t]{7}{*}{$2 \frac{1}{4} \mathrm{Cr} 1 \mathrm{Mo}$} & $1250^{\circ} \mathrm{C}-3$ days normalised & $\mathrm{W}$ & & & \\
\hline & $600^{\circ} \mathrm{C}-0.1 \mathrm{~h}$ tempered & VS & & & \\
\hline & $600^{\circ} \mathrm{C}-0.5 \mathrm{~h}$ tempered & VS & & & \\
\hline & $600^{\circ} \mathrm{C}-1.0 \mathrm{~h}$ tempered & VS & & & \\
\hline & $600^{\circ} \mathrm{C}-10 \mathrm{~h}$ tempered & VS & VW & & \\
\hline & $600^{\circ} \mathrm{C}-200 \mathrm{~h}$ tempered & VS & $\mathrm{W}$ & VW & \\
\hline & $600^{\circ} \mathrm{C}-1000 \mathrm{~h}$ tempered & VS & $\mathrm{W}$ & S & vw \\
\hline \multirow[t]{6}{*}{$3 \mathrm{Cr} 1.5 \mathrm{Mo}$} & $1250^{\circ} \mathrm{C}-3$ days normalised & $\mathrm{W}$ & & & \\
\hline & $600^{\circ} \mathrm{C}-0.05 \mathrm{~h}$ tempered & W & & & \\
\hline & $600^{\circ} \mathrm{C}-0.3 \mathrm{~h}$ tempered & VS & & W & \\
\hline & $600^{\circ} \mathrm{C}-0.7 \mathrm{~h}$ tempered & VS & VW & $\mathrm{S}$ & \\
\hline & $600{ }^{\circ} \mathrm{C}-10 \mathrm{~h}$ tempered & $\mathrm{S}$ & $\mathrm{W}$ & $\mathrm{S}$ & W \\
\hline & $600{ }^{\circ} \mathrm{C}-100 \mathrm{~h}$ tempered & $\mathrm{W}$ & $\mathrm{S}$ & $\mathrm{S}$ & $\mathrm{S}$ \\
\hline
\end{tabular}

in $2 \frac{1}{4} \mathrm{Cr} 1 \mathrm{Mo}$ steel remained rather weak even after $1000 \mathrm{~h}$, while that in $3 \mathrm{Cr} 1.5 \mathrm{Mo}$ steel was relatively strong after just $100 \mathrm{~h}$ of tempering heat treatment. As Robson ${ }^{1)}$ implied, the approach to equilibrium was faster in $3 \mathrm{Cr} 1.5 \mathrm{Mo}$ steel than in $2 \frac{1}{4}$ Cr1 Mo steel.

As a result, the precipitation sequences at $600^{\circ} \mathrm{C}$ for both steels are as follows:

$$
\begin{aligned}
2 \frac{1}{4} \mathrm{Cr} 1 \mathrm{Mo} ; & \mathrm{M}_{3} \mathrm{C} \rightarrow \mathrm{M}_{3} \mathrm{C}+\mathrm{M}_{2} \mathrm{C} \rightarrow \mathrm{M}_{3} \mathrm{C}+\mathrm{M}_{2} \mathrm{C}+\mathrm{M}_{7} \mathrm{C}_{3} \rightarrow \mathrm{M}_{3} \mathrm{C}+ \\
& \mathrm{M}_{2} \mathrm{C}+\mathrm{M}_{7} \mathrm{C}_{3}+\mathrm{M}_{23} \mathrm{C}_{6} \\
& \\
3 \mathrm{Cr} 1.5 \mathrm{Mo} ; & \mathrm{M}_{3} \mathrm{C} \rightarrow \mathrm{M}_{3} \mathrm{C}+\mathrm{M}_{7} \mathrm{C}_{3} \rightarrow \mathrm{M}_{3} \mathrm{C}+\mathrm{M}_{7} \mathrm{C}_{3}+\mathrm{M}_{2} \mathrm{C}+ \\
& \mathrm{M}_{23} \mathrm{C}_{6} \rightarrow \mathrm{M}_{7} \mathrm{C}_{3}+\mathrm{M}_{2} \mathrm{C}+\mathrm{M}_{23} \mathrm{C}_{6}
\end{aligned}
$$

These carbide sequences obtained here are in good agreement with the previous experimental work by Nutting et al. ${ }^{18,19)}$ and Klueh et al. ${ }^{20)}$

\subsection{TEM Observations}

- Morphology of Alloy Carbides

Figure 1 shows transmission electron micrographs of specimens tempered for $100 \mathrm{~h}$ or $200 \mathrm{~h}$ at a variety of temperatures for both steels. Apart from the specimens tempered at $700^{\circ} \mathrm{C}$, the micrographs predominantly show needle-shaped precipitates within the martensite laths. Small and blocky spherical precipitates can be found on the lath boundaries. Tempering at $700^{\circ} \mathrm{C}$, however, leads mainly to blocky precipitates with few needles.

$\mathrm{M}_{3} \mathrm{C}$ can be found in the early tempering stage as a diskshape or bar-shape within laths and at the lath boundaries.

$\mathrm{M}_{2} \mathrm{C}$ could easily be identified from its needle shape within the laths.

$\mathrm{M}_{7} \mathrm{C}_{3}$ occurred as blocky almost spherical particles on the lath boundaries. The shape of $\mathrm{M}_{7} \mathrm{C}_{3}$ can be assumed as sphere. As indicated by Beech et al. ${ }^{21)} \mathrm{M}_{7} \mathrm{C}_{3}$ particles often have a faulted structure so that streaks normal to the fault planes can be in its electron diffraction pattern.

$\mathrm{M}_{23} \mathrm{C}_{6}$ precipitated as a relatively sphere-like particle on the lath boundaries. It can be found clearly as a blocky particles in the $3 \mathrm{Cr} 1.5 \mathrm{Mo}$ steel tempered at $700^{\circ} \mathrm{C}$.

\section{Modelling Carbide Kinetics}

\subsection{Cementite Precipitation}

Most part of cementite precipitation, paraequilibrium formation, its subsequent enrichment and dissolution, will be treated by the same way of Robson and Bhadeshia model, ${ }^{1)}$ although some of microstructual parameters, thickness and the nucleation number density of cementite have been modified with the help of recent experimental data. ${ }^{9)}$

\section{- Paraequilibrium Formation}

Cementite precipitation from supersaturated martensite occurs rapidly even at very low temperatures. This is because it forms by a mechanism which does not involve the diffusion of substitutional solutes or iron atoms, but just the interstitial carbon atom. ${ }^{22}$ ) The ratio of iron to substitutional solute atoms does not therefore change during this paraequilibrium $^{22-24)}$ transformation. In general, this ratio is far less than demanded by equilibrium.

In the context of power plant steels, the time period for cementite precipitation is so small that it can be assumed 

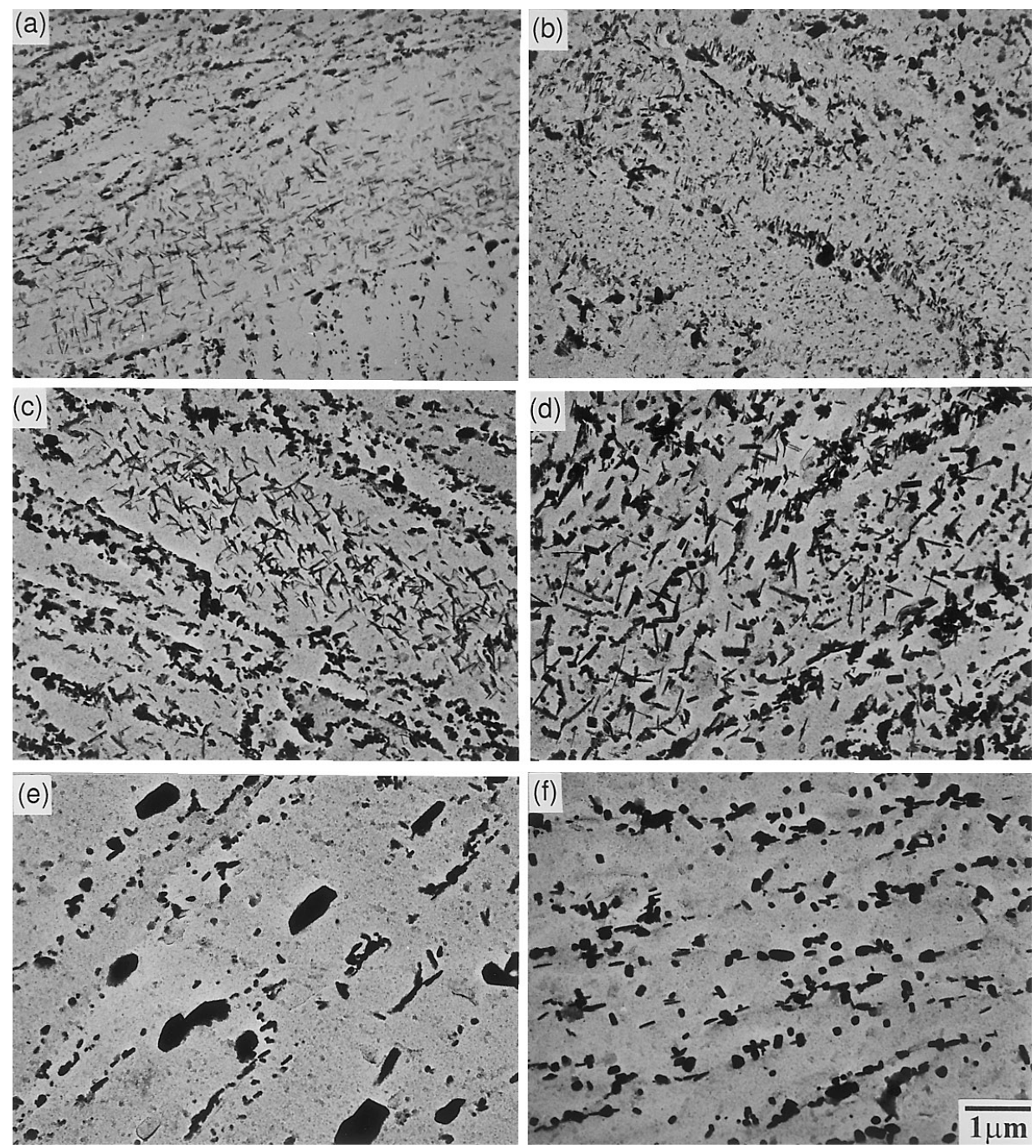

Fig. 1. Transmission electron micrographs for (a) $3 \mathrm{Cr} 1.5 \mathrm{Mo}$ and (b) $2 \frac{1}{4} \mathrm{Cr} 1 \mathrm{Mo}$ tempered at $600^{\circ} \mathrm{C}$ for $200 \mathrm{~h}$, (c) $3 \mathrm{Cr} 1.5 \mathrm{Mo}$ and (d) $2 \frac{1}{4} \mathrm{Cr} 1 \mathrm{Mo}$ tempered at $650^{\circ} \mathrm{C}$ for $100 \mathrm{~h}$, (e) $3 \mathrm{Cr} 1.5 \mathrm{Mo}$ and (f) $2 \frac{1}{4} \mathrm{Cr} 1 \mathrm{Mo}$ tempered at $700^{\circ} \mathrm{C}$ for $100 \mathrm{~h}$.

that the starting microstructure already contains precipitates of cementite with paraequilibrium transformation.

\section{- Enrichment}

The chemical composition of the cementite adjusts towards equilibrium from paraequilibrium during the heat treatment needed to induce alloy carbide precipitation. This process depletes the matrix of substitutional solute and hence must be taken into account in any model for alloy carbide precipitation. The theory for the enrichment of a cementite particle of thickness $d$ has been described by Bhadeshia $^{25)}$ :

$$
t_{\mathrm{c}}^{1 / 2}=\frac{d \pi^{1 / 2}\left(\bar{c}-c_{t}\right)}{4 D^{1 / 2}\left(c^{\theta \alpha}-\bar{c}\right)}
$$

where $c_{t}$ is the mean composition of the cementite (designated $\theta$ at time $t_{\mathrm{c}}, D$ is the diffusion coefficient for the solute concerned and $c^{\theta \alpha}$ is the concentration in $\theta$ which is in equilibrium with the matrix $\alpha$. Recent experiments indicated that the thickness of cementite is different when precipitated at the martensite lath boundaries $(\simeq 50 \mathrm{~nm})$ when compared with that precipitated within the laths $(\simeq 20 \mathrm{~nm})$ for $3 \mathrm{Cr} 1.5 \mathrm{Mo}$ steel. ${ }^{9)}$ These are the values assumed in the present work and the particles at the boundaries have been modelled as a separate phase from those within the laths.

\section{- Site Density}

The volume fraction of cementite must depend on the carbon content, so it is reasonable to assume that the number density of cementite particles can also be expressed as a function of carbon content. The number density of cementite particles per unit volume $N_{0 \theta}$ is found experimentally to be given by ${ }^{9}$ :

$$
N_{0 \theta}=2.23 \times 10^{22} w_{\mathrm{C}}-10^{21} \mathrm{~m}^{-3}
$$

where $w_{\mathrm{C}}$ is the concentration of carbon in $\mathrm{wt} \%$. This empirical equation was established using $0.15 \mathrm{wt} \% \mathrm{C}-$ $2 \frac{1}{4} \mathrm{Cr} 1 \mathrm{Mo}$ and $0.10 \mathrm{wt} \% \mathrm{C}-3 \mathrm{Cr} 1.5 \mathrm{Mo}$ steels, so it might reasonably be expected to apply to tempered martensitic steels with carbon concentrations in the range from 0.10 to 0.15 wt $\%$.

\section{- Dissolution}

The cementite $\theta$ eventually must begin to dissolve as the precipitation of the thermodynamically more stable alloy carbide $\beta$ gathers pace. The dissolution of cementite provides a source of solute for the growing alloy carbide. The 
dissolution for each particle begins when the mean concentration $\bar{c}$ becomes less than $c^{\alpha \theta}$, thereby driving the diffusion of solute from the cementite to each alloy carbide. The dissolution velocity $v_{\mathrm{d}}$ is given by ${ }^{1)}$ :

$$
v_{\mathrm{d}}\left(c^{\theta \alpha}-c^{\alpha \theta}\right)=D \frac{c^{\alpha \theta}-c_{\mathrm{r}}^{\alpha \beta}}{\bar{d}}
$$

where $c^{\alpha \theta}$ and $c^{\theta \alpha}$ are the solute concentrations in the ferrite and cementite at the interface between ferrite matrix $\alpha$ and cementite. The mean distance between the cementite and each alloy carbide particle $\bar{d}$ is given by:

$$
\bar{d}=\left(N_{\theta}+N_{\beta}\right)^{-1 / 3}
$$

where $N_{\theta}$ and $N_{\beta}$ are the number densities of cementite and alloy carbide particles respectively.

\subsection{Alloy Carbide Precipitation}

\section{- Nucleation}

The nucleation is assumed to occur with a constant nucleation rate when soft-impingement does not occur. Classical nucleation theory ${ }^{11)}$ is used to estimate the nucleation rate $I^{\prime}$ for alloy carbide together with the site consumption:

$$
\begin{array}{r}
I^{\prime}=\bar{c}\left(1-\frac{V^{\prime}}{V^{\text {eq }}}\right) N_{0 \beta} \frac{k T}{h} \exp \left\{-\frac{G^{*}+Q^{*}}{k T}\right\} . \\
G^{*}=\frac{16 \pi \sigma^{3}}{3\left(\Delta G_{\mathrm{v}}\right)^{2}} \ldots \ldots \ldots \ldots \ldots \ldots \ldots \ldots \ldots \ldots \ldots \ldots \ldots
\end{array}
$$

where $V^{\prime}$ and $V^{\text {eq }}$ are instantaneous and equilibrium fractions of alloy carbide respectively, $N_{0 \beta}$ is the number density of nucleation sites for alloy carbide, $h$ and $k$ are the Planck and Boltzmann constants respectively, $Q^{*}$ is the activation energy for the transfer of atoms across the nucleus/matrix interface, assumed to be the activation energy for volume diffusion. ${ }^{11)} T$ is the absolute temperature and $\Delta G_{\mathrm{v}}$ is the chemical free energy change per unit volume. $\sigma$ is the interfacial energy per unit area between the precipitate and the matrix. In this model, $N_{0 \beta}$ and $\sigma$ were used as fitting parameters.

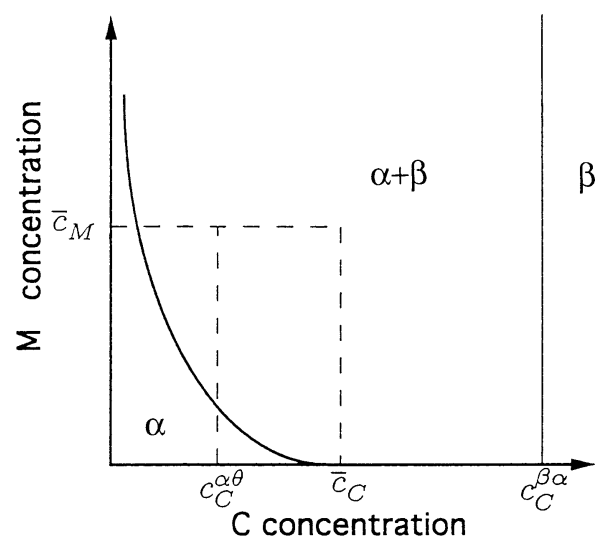

Fig. 2. A schematic isothermal section through the $\mathrm{Fe}-\mathrm{M}-\mathrm{C}$ phase diagram, showing the ferrite matrix $\alpha$ and alloy carbide $\beta$ phase fields.
- Tie-line Shifting by Soft-impingement

Figure 2 shows a schematic isothermal section of the $\mathrm{Fe}-\mathrm{M}-\mathrm{C}$ phase diagram. The alloy has an average carbon concentration which is $\bar{c}_{\mathrm{C}}$ but the carbon left in solution in the ferrite when cementite has precipitated, $c_{\mathrm{C}}^{\alpha \theta}$ is the smaller concentration of carbon which is initially available for the alloy carbide precipitation.

There are two ways in which the mass conservation equations for substitutional solute $\mathrm{M}$ and carbon $\mathrm{C}$ can be satisfied simultaneously. The first is to choose a tie-line which greatly increases the gradient of solute $M$ to compensate for its low diffusivity. This would require the carbide to have virtually the same solute concentration as the matrix with very little partitioning of solute $M$, but with a sharp concentration spike at the interface in order to maintain local equilibrium (NP-LE). This situation is only possible at very large driving forces. ${ }^{12,13)}$ The case of power plant steels refers, on the other hand, to precipitation at low supersaturations. In these circumstances, the only alternative is to choose a tie-line which reduces the gradient of carbon to such an extent that the flux of carbon is reduced to a level consistent with that of solute $M$. Following Coates, ${ }^{12)}$ this can be done by drawing the iso-activity line, approximately a vertical construction line through the point $b$ in Fig. 3 when $D_{\mathrm{M}} \ll D_{\mathrm{C}}$, which represents the composition of the ferrite from which each alloy carbide will precipitate. The intersection of the vertical line with the $\alpha /(\alpha+\beta)$ phase field defines completely the tie-line which fixes the interface compositions in a manner which satisfies the two mass conservation conditions simultaneously because the large diffusion coefficient of carbon is compensated for by the very small concentration gradient of carbon. ${ }^{12,13)}$ Note that this also maintains local equilibrium at the interface since the compositions at the interface (given by the points $\mathrm{c}$ and $\mathrm{d}$ for $\alpha$ and $\beta$ respectively) are connected by a tieline of the phase diagram.

Each alloy carbide precipitation must deplete the solute concentration in the matrix (soft-impingement). The locus of the matrix composition at any instant is along the direction $b \rightarrow e$ (Fig. 3). Any change in the matrix composition

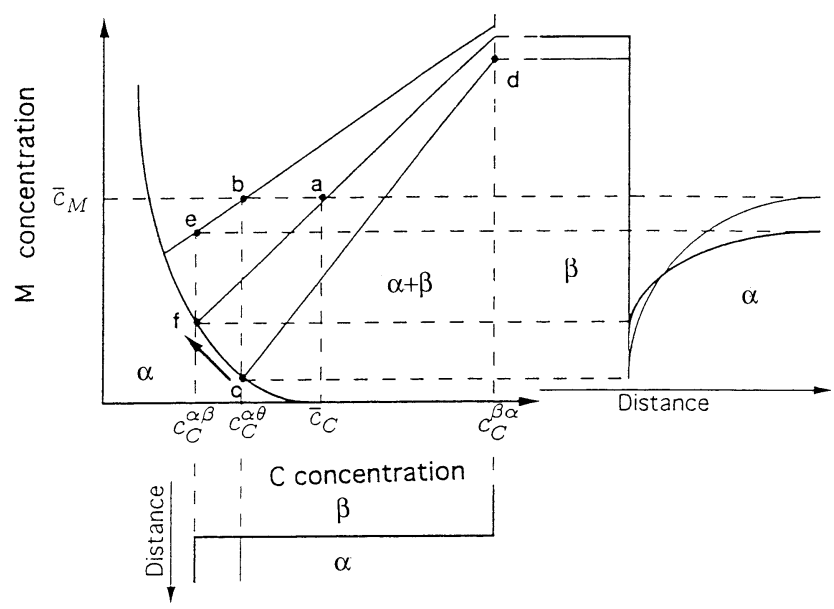

Fig. 3. A schematic isothermal section through the $\mathrm{Fe}-\mathrm{M}-\mathrm{C}$ phase diagram, showing the ferrite matrix $\alpha$ and alloy carbide $\beta$ fields. The alloy composition is plotted as point a whereas the composition of the ferrite after the precipitation of cementite is designated $b$. 
also leads to a different choice of tie-line, the locus of $c^{\alpha \beta}$ being along $\mathrm{c} \rightarrow \mathrm{f}$. This tie-line shifting ${ }^{12)}$ continues until the reaction stops when the tie-line intersects the average composition a and $c^{\alpha \beta}=\mathbf{f}$.

\section{- Thermodynamic Calculation}

The driving forces for each alloy carbide formation and the relevant phase boundaries were calculated using MTDATA. ${ }^{17)}$

All reactions assume to start at the time $t=0$ but occur at different rates so that the driving forces must at first be described to the initial microstructure with paraequilibrium cementite $\mathrm{M}_{3} \mathrm{C}_{\text {para }}$.

$$
\begin{gathered}
\alpha+\mathrm{M}_{3} \mathrm{C}_{\mathrm{para}} \rightarrow \alpha^{\prime}+\mathrm{M}_{2} \mathrm{C} \\
\alpha+\mathrm{M}_{3} \mathrm{C}_{\mathrm{para}} \rightarrow \alpha^{\prime \prime}+\mathrm{M}_{7} \mathrm{C}_{3} \\
\alpha+\mathrm{M}_{3} \mathrm{C}_{\mathrm{para}} \rightarrow \alpha^{\prime \prime \prime}+\mathrm{M}_{23} \mathrm{C}_{6}
\end{gathered}
$$

where $\alpha^{\prime}, \alpha^{\prime \prime}$ and $\alpha^{\prime \prime \prime}$ represent the ferrite coexisting with $\mathrm{M}_{2} \mathrm{C}, \mathrm{M}_{7} \mathrm{C}_{3}$ and $\mathrm{M}_{23} \mathrm{C}_{6}$ respectively. The free energy change for each reaction $\Delta G_{0}$ was calculated as a function of temperature. The driving force per volume of precipitate can be obtained by dividing the free energy change for each reaction by the equilibrium volume fraction of the precipitation.

All of the alloy carbides contain certain amount of chromium in both steels ${ }^{16)}$ so that $\mathrm{Cr}$ was selected as the diffusive solute $\mathrm{M}$ during the diffusion-controlled growth not in Fe-M binary system but in a multicomponent system. Then, $\mathrm{Cr}$ equilibrium concentration at the planner interface between matrix $\alpha$ and $i$ th $c_{\mathrm{Cr}}^{a i}$ carbide were also calculated using MTDATA. ${ }^{17)}$

\section{- Mean Field Approximation}

Alloy carbide formation is likely to be controlled by the diffusion of substitutional solute atoms. The change of matrix composition during precipitation can affect the subsequent nucleation and growth process. Although some complex solutions have been suggested, ${ }^{26)}$ for avoiding complexity, Robson and Bhadeshia suggested the mean field approximation for soft-impingement. ${ }^{1)}$ Solute concentration changes are averaged at over the remaining matrix phase as a method for dealing with soft-impingement. ${ }^{1)}$ The dimensionless supersaturation is written:

$$
V^{\mathrm{Max}}=\frac{\left(\bar{c}-c^{\alpha \beta}\right)}{\left(c^{\beta \alpha}-c^{\alpha \beta}\right)}
$$

where $V^{\mathrm{Max}}$ is the maximum fraction for each phase. The effect of soft-impingement in the mean field approximation may be expressed in terms of an "extent of reaction" parameter, defined as:

$$
\Phi=V^{\prime} / V^{\mathrm{Max}}
$$

where $V^{\prime}$ is the fraction at any instance for each phase. Therefore, $\Phi$ changes from 0 to 1 during precipitation and can be defined for each phase. For simultaneous precipitation, $\Phi$ may be changed by occurrence of a new phase precipitating. If there are $n$ phases forming simultaneously, then $\Phi_{i}$ for the $i$ th phase is given by:

$$
\Phi_{i}=\frac{\sum_{i=1}^{n} V_{i}^{\prime}\left(c^{i \alpha}-c^{\alpha i}\right)}{\left(\bar{c}-c^{\alpha i}\right)}
$$

where $c^{i \alpha}$ and $c^{\alpha i}$ are concentrations at the interface between $i$ th phase and matrix $\alpha$ in the $i$ th phase and in the matrix respectively, $V_{i}^{\prime}$ is the fraction at any instance for the $i$ th phase.

Physically, $\Phi$ represents the fraction of excess solute remaining in the matrix with respect to the phase in question. Therefore, it is possible to make an approximation that the driving force $\Delta G_{i}$ for formation of each phase should be in proportion to $\left(1-\Phi_{i}\right)$ as indicated in Eq. (13).

$$
\Delta G_{i}=\left(1-\Phi_{i}\right) \Delta G_{0 i}
$$

where $\Delta G_{0 i}$ is the driving force at $t=0$.

For $\mathrm{M}_{3} \mathrm{C}$, it must be necessary to calculate the value of $\Phi_{\mathrm{M}_{3} \mathrm{C}}$ differently. This is because $\mathrm{M}_{3} \mathrm{C}$ nucleates with the paraequilibrium composition. Therefore, the value should include the composition change of diffusing solute atom.

$$
\Phi_{\mathrm{M}_{3} \mathrm{C}}=\frac{\left(c-\bar{c}^{\prime}\right)}{\left(c^{\mathrm{M}_{3} \mathrm{C} \alpha}-\bar{c}^{\prime}\right)}
$$

where $\bar{c}^{\prime}$ is the mean concentration in the matrix at any time, which is

$$
\bar{c}^{\prime}=\frac{\left(\bar{c}-\sum_{i=1}^{n} V_{i}^{\prime} c^{i \alpha}\right)}{\left(1-\sum_{n=1}^{n} V_{i}^{\prime}\right)}
$$

Schematic composition profiles are shown in Fig. 4, (a) at a certain time, both $\beta$ and $\gamma$ are precipitating in matrix $\alpha$ and then (b) when solute concentration in matrix reaches

(a)

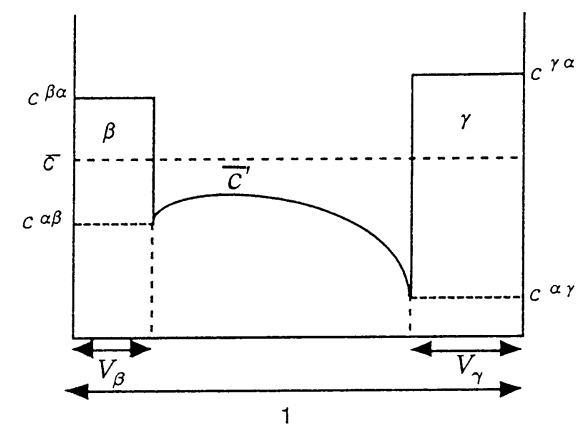

(b)

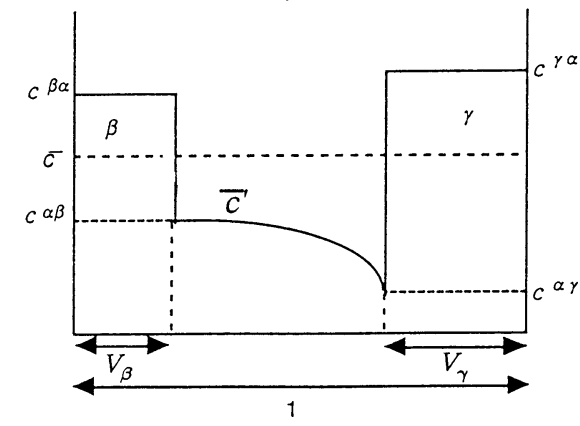

Fig. 4. Distribution of solute when (a) both $\beta$ and $\gamma$ are precipitating, and (b) where the precipitation of $\beta$ has been completed. ${ }^{1)}$ Note that $\bar{c}^{\prime}$ is solute concentration in the matrix $\alpha$ and that $V_{\beta}$ and $V_{\gamma}$ are phase volume fraction for $\beta$ and $\gamma$ respectively. 


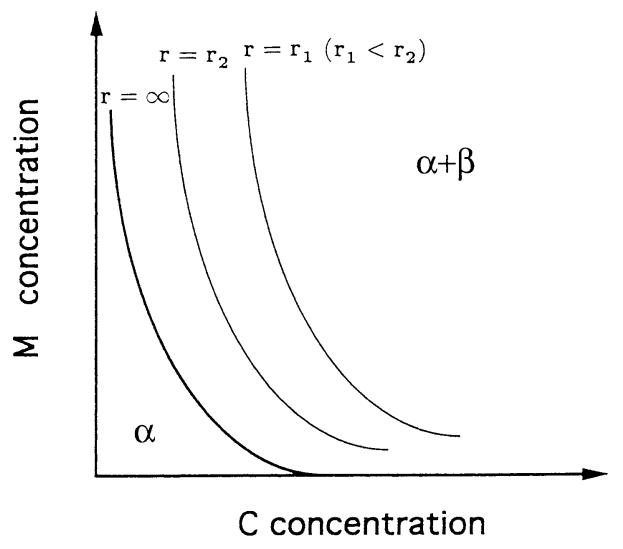

Fig. 5. A schematic illustration of the way the $\alpha / \alpha+\beta$ phase boundary changes for a variety of values for radius of curvature $r$ at the interface.

Table 4. The calculated tip radii of $\mathrm{M}_{2}(\mathrm{C}, \mathrm{N})$ for each element in $10 \mathrm{Cr}$ wt\% power plant steel by Eq. (18). ${ }^{16)}$

\begin{tabular}{|c|ccccc|}
\hline & Cr & Fe & Mo & C & N \\
\hline $\mathrm{r} / \AA$ & 913.2 & 230.1 & 1039.4 & 0.318 & 0.170 \\
\hline
\end{tabular}

the equilibrium with $\beta$, precipitation of $\beta$ has been completed, and as $\gamma$ precipitates further, removing solute, $\beta$ will start to dissolve.

- Capillarity Effect on Alloy Carbide Formation

The growth rate of needle-shaped precipitates will be given by ${ }^{15)}$ :

$$
v=\frac{D \Omega_{\mathrm{r}}}{z_{\mathrm{d}}} \text { with } \Omega_{\mathrm{r}}=\frac{\bar{c}-c_{\mathrm{r}}^{\alpha \beta}}{c^{\beta \alpha}-c_{\mathrm{r}}^{\alpha \beta}}
$$

for

$$
z_{\mathrm{d}}=\frac{2\left(c^{\beta \alpha}-\bar{c}\right)}{\left(c^{\beta \alpha}-c_{\mathrm{r}}^{\alpha \beta}\right)} r
$$

where $\Omega_{\mathrm{r}}$ is dimensionless supersaturation with capillarity effect. Therefore, another theory, capillarity effect, still be necessary to obtain velocity of needle-shaped precipitates.

The method developed here to account for the capillarity effect in a multicomponent system involves the calculations of the $\alpha / \alpha+$ needle-shaped precipitates $(\beta)$ boundary on the isothermal section of the phase diagram, as a function of the radius of the curvature $r$ at the interface. Equation (4) is used to calculate the concentration affected by capillarity effect $c_{\mathrm{r}}^{\alpha \beta}$ for a fixed value of the interface radius of curvature. The growth velocity of needles is then calculated using the method described in the previous section but with the curvature-modified phase boundary (Fig. 5).

A problem of the tip radius in a multicomponent system still remains. As Robson had calculated, ${ }^{16)}$ the values of the tip radius $r$ for each solute were not unique but very different from each other. Table 4 shows the calculation results by Robson about the tip radius for $\mathrm{M}_{2}(\mathrm{C}, \mathrm{N})$ in a $10 \mathrm{Cr} \mathrm{wt} \%$ power plant steel with Eq. (18):

$$
r=\frac{4 c^{\alpha \beta} \Gamma}{\left(\bar{c}-c^{\alpha \beta}\right)} \quad \text { with } \Gamma=\left(\frac{\sigma v^{\beta}}{k T}\right)\left(\frac{1-c^{\alpha \beta}}{\bar{c}-c^{\beta \alpha}}\right)
$$

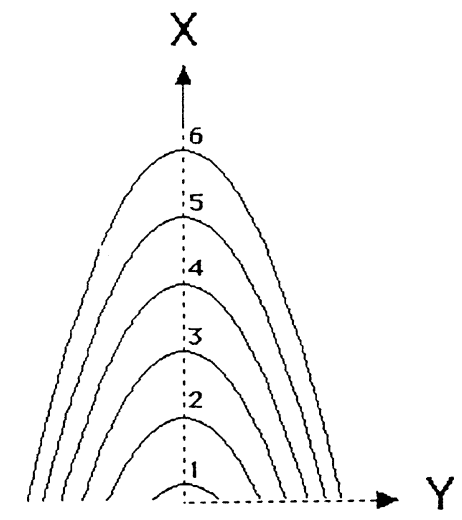

Fig. 6. A schematic illustration for the particle shape at the tip in which shape-preserving is assumed to be the same parabola along $\mathrm{X}$. The sequence $1-6$ along $\mathrm{X}$ illustrates the nature of the shape-preserving solution with constant growth rate. ${ }^{27)}$

Physically, the tip radius should be unique for a particle. Trivedi's solution preserves the shape of the parabola at the particle tip with constant growth rate as shown in Fig. 6. ${ }^{27)}$ The tip radius remains constant in the absence of soft-impingement. The problem here is how to decide the value of $r$ and hence fix the velocity. Small tip radius makes fast velocity but this is opposite to capillarity effect since the driving force for growth became zero when $r \rightarrow r_{\mathrm{c}}$. Therefore, the additional theory or assumption is needed. Zener proposed the velocity will go through maximum, ${ }^{28)}$ although there is not a fundamental basis.

In this way, the interface velocity can be plotted as a function of the radius $r$; such a function must go through a maximum because a large radius approximates to one-dimensional diffusion confined to regions normal to the interface, whereas the capillarity effect reduces the velocity as $r$ approaches to the critical radius $r_{\mathrm{c}}$ at which growth stops. The maximum velocity can be obtained numerically and then be assumed to correspond to the actual growth velocity, an assumption known as the Zener hypothesis. ${ }^{28)}$

The spherical precipitates are assumed to grow under the parabolic law with time. For low supersaturations, the change of particle radius $r$ with time is given approximately by ${ }^{15)}$ :

$$
r=\alpha_{3} \sqrt{D t} \text { with } \alpha_{3} \simeq \sqrt{2 \frac{\bar{c}-c^{\alpha \omega}}{c^{\omega \alpha}-\bar{c}}}
$$

where $\alpha_{3}$ is called the three-dimensional parabolic rate constant.

For spherical particles, the curvature of radius at the interface $\alpha / \alpha+$ spherical precipitates $(\omega) r$ should correspond to particle radius so that the modified composition $c_{\mathrm{r}}^{\alpha \omega}$ is easy to estimate compared with the case of needles. The method used here to account for the capillarity effect in a multicomponent system involves the calculations of the $\alpha / \alpha+\omega$ boundary on the isothermal section of the phase diagram, as a function of the particle radius $r$ of the interface. Equation (4) is used to calculate $c_{\mathrm{r}}^{\alpha \omega}$ with a value of the particle radius for each particle. The growth velocity can then be calculated using the curvature-modified phase boundary in the same way of the needle-shaped precipitates 
Table 5. Parameter values used in the new model.

\begin{tabular}{|c|c|}
\hline The microstructural parameters & The values in use \\
\hline Number density of sites for $\mathrm{M}_{3} \mathrm{C}$ in 3Cr1.5Mo steel & $1.23 \times 10^{21} \mathrm{~m}^{-3}$ \\
Number density of sites for $\mathrm{M}_{2} \mathrm{C}$ in 3Cr1.5Mo steel & $6.15 \times 10^{19} \mathrm{~m}^{-3}$ \\
Number density of sites for $\mathrm{M}_{7} \mathrm{C}_{3}$ in 3Cr1.5Mo steel & $4.92 \times 10^{19} \mathrm{~m}^{-3}$ \\
Number density of sites for $\mathrm{M}_{23} \mathrm{C}_{6}$ in 3Cr1.5Mo steel & $9.84 \times 10^{19} \mathrm{~m}^{-3}$ \\
Number density of sites for $\mathrm{M}_{3} \mathrm{C}$ in $2 \frac{1}{4} \mathrm{Cr} 1 \mathrm{Mo}$ steel & $2.35 \times 10^{21} \mathrm{~m}^{-3}$ \\
Number density of sites for $\mathrm{M}_{2} \mathrm{C}$ in $2 \frac{1}{4} \mathrm{Cr} 1 \mathrm{Mo}$ steel & $1.41 \times 10^{19} \mathrm{~m}^{-3}$ \\
Number density of sites for $\mathrm{M}_{7} \mathrm{C}_{3}$ in $2 \frac{1}{4} \mathrm{Cr} 1 \mathrm{Mo}$ steel & $4.70 \times 10^{19} \mathrm{~m}^{-3}$ \\
Number density of sites for $\mathrm{M}_{23} \mathrm{C}_{6}$ in $2 \frac{1}{4} \mathrm{Cr} 1 \mathrm{Mo}$ steel & $4.70 \times 10^{19} \mathrm{~m}^{-3}$ \\
\hline Thickness of $\mathrm{M}_{3} \mathrm{C}$ on lath boundaries for both steels & $5.0 \times 10^{-8} \mathrm{~m}^{-8} \mathrm{~m}^{-3}$ \\
Thickness of $\mathrm{M}_{3} \mathrm{C}$ within laths for both steels & $2.0 \times 10^{-8} \mathrm{~m}^{-2}$ \\
\hline Interfacial energy of $\mathrm{M}_{2} \mathrm{C}$ & $0.200 \mathrm{~J} \mathrm{~m}^{-2}$ \\
Interfacial energy of $\mathrm{M}_{7} \mathrm{C}_{3}$ & $0.256 \mathrm{~J} \mathrm{~m}^{-2}$ \\
Interfacial energy of $\mathrm{M}_{23} \mathrm{C}_{6}$ & $0.277 \mathrm{~J} \mathrm{~m}^{-2}$ \\
\hline$D_{0}$ in diffusion coefficient for Cr & $1.5 \times 10-4 \mathrm{~m}^{2} \mathrm{~s}^{-1}$ \\
Activation energy for Cr diffusion & $240 \times 10^{3} \mathrm{~J} \mathrm{~mol}^{-1}$ \\
\hline
\end{tabular}

Table 6. Comparison of assumptions used in both models.

\begin{tabular}{|c|c|}
\hline Robson and Bhadeshia model ${ }^{1)}$ & New model \\
\hline - Based on Avrami theory & - Nucleation and growth but no treatment of impingement \\
& - Nucleation site consumption \\
- Using mean particle size & - Particle size distribution due to \\
& different nucleation times and growth rates \\
- Cr diffusion-controlled growth & - Diffusion-controlled growth in a multicomponent system \\
- No treatment of capillarity effect & - Capillarity effect in a multicomponent system \\
\hline
\end{tabular}

(Fig. 5).

Spherical particles which are smaller than the size of a critical nucleus obviously cannot grow. Nucleation occurs by random fluctuations so that the growth part in the computational scheme must start beyond the nucleation stage. Alloy carbide precipitation leads to a depletion of solute in the matrix so that the mean concentration of solute at any instance $\bar{c}^{\prime}$ must decrease as precipitation reactions progress. This is soft-impingement which is treated using the mean field approximation and then $\bar{c}^{\prime}$ is given by Eq. (15).

Spherical particles nucleate at different times during the course of reaction, giving rise to a distribution of sizes. At any given stage of precipitation the small particles will grow at a smaller rate than a big particle because of the capillarity effect which reduces the supersaturation for small particles. The condition that particles nucleated can grow is given by:

$$
\left(\bar{c}^{\prime}-c_{\mathrm{r}}^{\alpha \omega}\right)>0 .
$$

When the situation almost reaches equilibrium, big particles may have higher solute concentrations at the interface $c_{\mathrm{r}}^{\alpha \omega}$ than the mean solute concentration in matrix $\bar{c}^{\prime}$ while small particles may have lower solute concentrations than $\bar{c}^{\prime}$. This in turn gives coarsening as a natural consequence of the precipitation theory.

This procedure solves all the problems described in the introduction. It deals correctly with mass balance for both the diffusing species and the capillarity corrected concentrations for each solute give the same tip radius when in- serted into Eq. (4).

\section{Comparison between Theory and Experiments}

\subsection{Parameters}

The measured microstructural parameters used in the new model are shown in Table $\mathbf{5}$ as well as fitting parameters. The diffusion coefficients listed by Fridberg et al. ${ }^{29)}$ were used in the calculations. Table 6 shows a comparison of the assumptions in the original and the modified model.

\subsection{Volume Fraction Change}

The calculations of volume fraction change for each carbide in both steels are shown in Fig. 7 along with the experimental observations. The new model correctly predicts the evolution of the carbide sequence.

\subsection{Particle Size Change}

Figure 8 shows a comparison between experimental data (points) and theory (curves) of the maximum $\mathrm{M}_{2} \mathrm{C}$ needle length. The calculations are reasonably consistent with experiments.

Figure 9 shows a comparison between experimental data (points) and theory (curves) of the mean $\mathrm{M}_{7} \mathrm{C}_{3}$ radius. The error bars on the experiments correspond to two standard deviations. Although there are detailed discrepancies, the results are reasonably consistent. It appears that the size of $\mathrm{M}_{7} \mathrm{C}_{3}$ is underestimated in the early stage of precititation and overestimated in the later stage of precipitation, while 

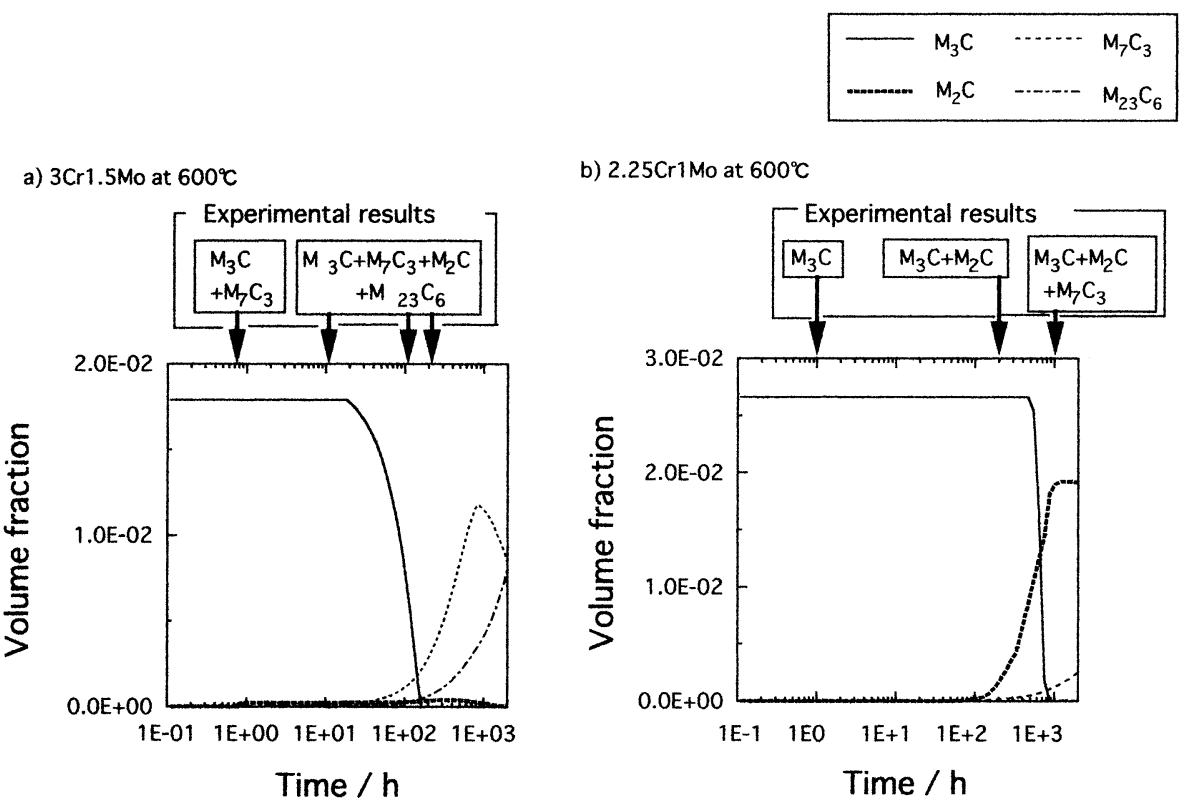

Fig. 7. Calculations of multiple precipitation reactions for (a) $3 \mathrm{Cr} 1.5 \mathrm{Mo}$ and (b) $2 \frac{1}{4} \mathrm{Cr} 1 \mathrm{Mo}$ steels at $600^{\circ} \mathrm{C}$ using the new model for both steels.
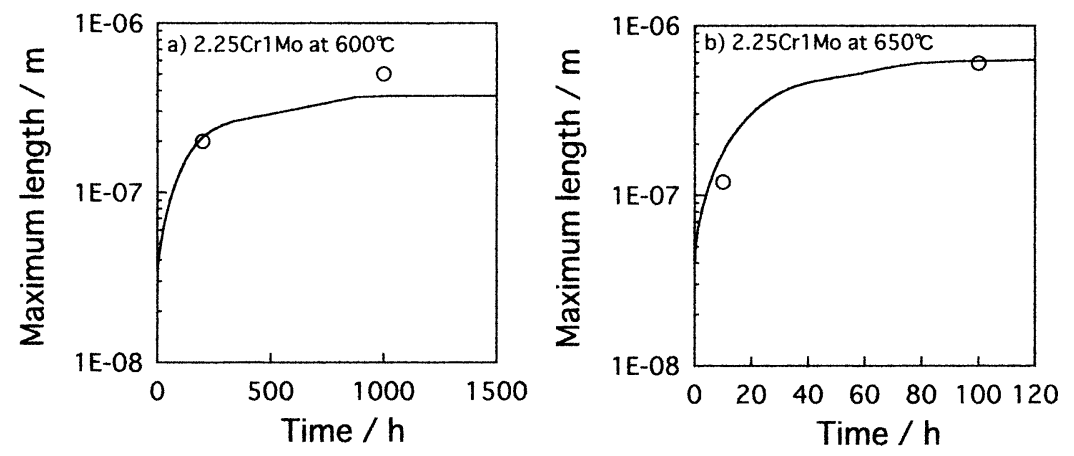

Fig. 8. Comparison of the measured maximum needle length of $\mathrm{M}_{2} \mathrm{C}$ versus calculations for $2 \frac{1}{4} \mathrm{Cr} 1 \mathrm{Mo}$ steels tempered at $600^{\circ} \mathrm{C}$ and $650^{\circ} \mathrm{C}$.

the calculations are almost within the limits of experimental uncertainties. One possible explanation is that $\mathrm{M}_{7} \mathrm{C}_{3}$ precipitates intragranularly and at the $\mathrm{M}_{3} \mathrm{C}$ boundaries. ${ }^{19,30)}$ The latter precipitates may form at greater rate and grow at slower rate than expected from the calculations, which do not allow for the specific nucleation site. These precipitates, such as formed at different sites, should be calculated separately.

Figure 10 shows a comparison between experimental data (points) and theory (curves) of the mean $\mathrm{M}_{23} \mathrm{C}_{6}$ radius. The error bars on the experiments correspond to two standard deviations. The results are reasonably consistent. $\mathrm{M}_{23} \mathrm{C}_{6}$ sometimes precipitates on grain boundaries and a collector-plate mechanism of diffusion may then dominate growth. ${ }^{31)}$ However, there are too many unknown parameters, e.g., area of collector-plate, in the collector-plate model and hence this complexity has been neglected in the present work.

\section{Summary}

A new model for multiple precipitation reactions has been established. It includes multicomponent treatments of both the diffusion-controlled growth and capillarity. The new calculations have been carried out without the Avrami conversion of extended space into real space, a satisfactory approximation given the minute fractions of precipitates involved. The new model shows good agreement with experimental data about not only volume fractions but also particle sizes for each alloy carbide in $3 \mathrm{Cr} 1.5 \mathrm{Mo}$ and $2 \frac{1}{4} \mathrm{Cr} 1 \mathrm{Mo}$ steels.

\section{Acknowledgements}

Authors would like to thank Professors A. H. Windle and C. J. Humphreys for the provision of laboratory facilities in the Department of Materials Science and Metallurgy at the University of Cambridge and would like to express my sincere thanks to Dr. J. D. Robson for his support throughout this work. One of authors (NF) thanks Mr. K. Kimura, a se- 

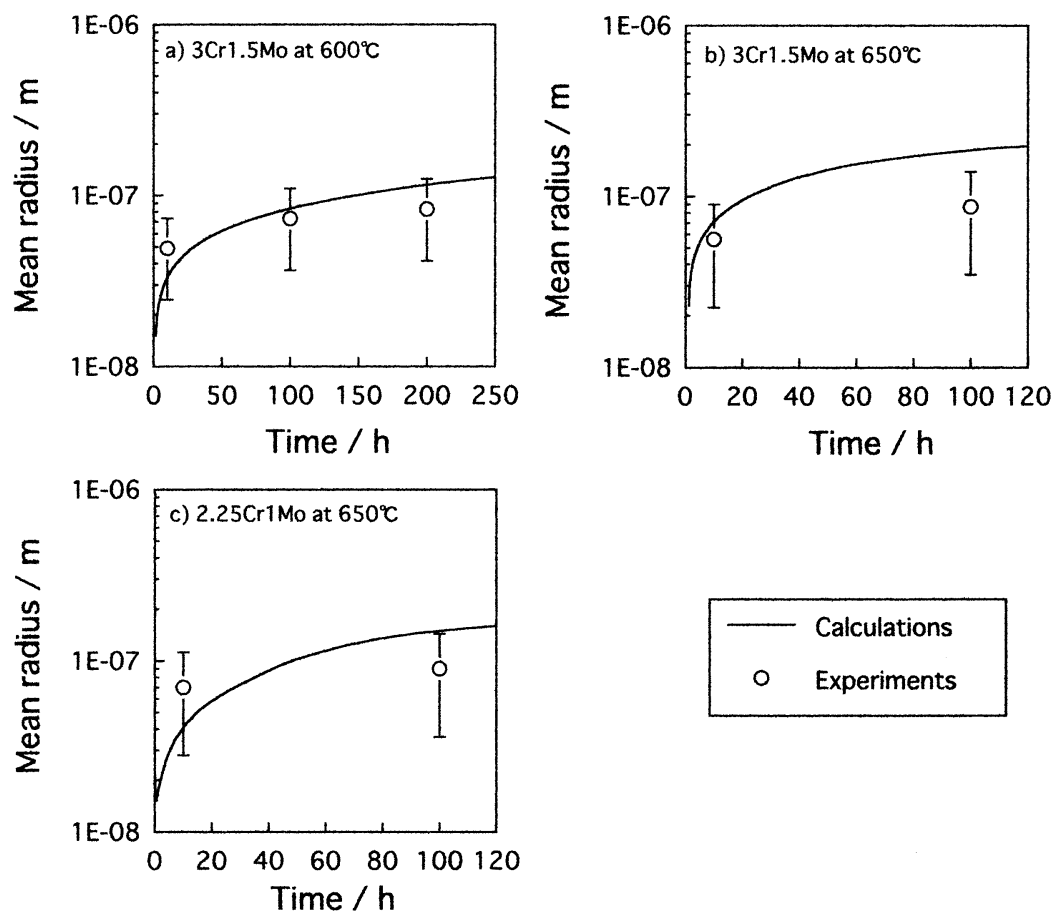

Fig. 9. Comparison of the measured mean radius of $\mathrm{M}_{7} \mathrm{C}_{3}$ versus calculations for $3 \mathrm{Cr} 1.5 \mathrm{Mo}$ and $2 \frac{1}{4} \mathrm{Cr} 1 \mathrm{Mo}$ steels tempered at $600^{\circ} \mathrm{C}$ and $650^{\circ} \mathrm{C}$. The error bars correspond to two standard deviations.

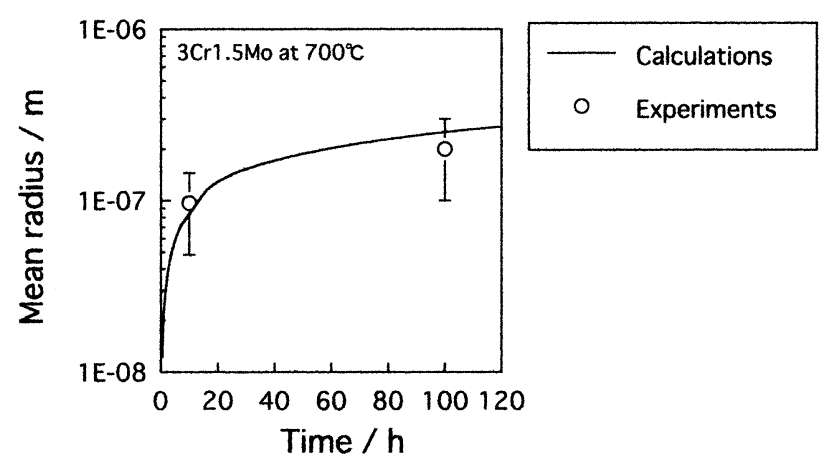

Fig. 10. Comparison of the measured mean radius of $\mathrm{M}_{23} \mathrm{C}_{6}$ versus calculations for $3 \mathrm{Cr} 1.5 \mathrm{Mo}$ and $2 \frac{1}{4} \mathrm{Cr} 1 \mathrm{Mo}$ steels tempered at $700^{\circ} \mathrm{C}$. The error bars correspond to two standard deviations.

nior reasercher in Nippon Steel Corp., for his great support in experimental work.

\section{REFERENCES}

1) J. D. Robson and H. K. D. H. Bhadeshia: Mater. Sci. Technol., 13 (1997), 631.

2) J. D. Robson and H. K. D. H. Bhadeshia: Mater. Sci. Technol., 13 (1997), 640.

3) S. J. Jones and H. K. D. H. Bhadeshia: Acta Metall., 45 (1997), 2911.

4) W. A. Johnson and R. F. Mehl: Trans. AIME, 135 (1939), 416.

5) M. Avrami: J. Chem. Phys., 7 (1939), 1103.

6) M. Avrami: J. Chem. Phys., 8 (1940), 212

7) M. Avrami: J. Chem. Phys., 9 (1941), 177.

8) A. N. Kolmogorov: Bulletin de L'Academie des Sciences de L'Urss.,
3 (1937), 355

9) N. Fujita and H. K. D. H. Bhadeshia: Advanced Heat Resistant Steel for Power Generation, ed. by R. Viswanathan and J. Nutting, The Institute of Materials, London, (1998), 223.

10) N. Fujita and H. K. D. H. Bhadeshia: Mater. Sci. Technol., 15 (1999), 627.

11) D. Turnbull and J. C. Fisher: J. Chem. Phys., 17 (1949), 71.

12) D. E. Coates: Metall. Trans., 4 (1977), 2313.

13) J. S. Kirkaldy: Can. J. Phys., 36 (1958), 907.

14) M. Hillert, K. Nilsson and L.-E. Törndahl: J. Iron Steel Inst., 209 (1971), 49.

15) J. W. Christian: Theory of Transformations in Metals and Alloys, Part 1, 2nd Ed., Pergamon Press, Oxford, (1975).

16) J. D. Robson: Ph. D. Thesis, University of Cambridge, UK, (1996).

17) S. M. Hodson: MTDATA-Metallurgical and Thermochemical Databank, National Physical Laboratory, Teddington, UK, (1989).

18) R. G. Baker and J. Nutting: J. Iron Steel Inst., 192 (1959), 257.

19) J. Nutting: Advanced Heat Resistant Steel for Power Generation, ed. by R. Viswanathan and J. Nutting, The Institute of Materials, London, (1998), 12.

20) R. L. Klueh and A. M. Nasreldin: Metall. Trans. A., 18A (1987), 1279.

21) J. Beech and D. H. Warrington: J. Iron Steel Inst., 204 (1966), 460.

22) A. Hultgren: Trans. ASM, 39 (1947), 915.

23) E. Rudberg: Jernkontorets Ann., 136 (1952), 91.

24) H. I. Aaronson and H. A. Domain: Trans. Metall. Soc. AIME, 236 (1966), 781.

$25)$ H. K. D. H. Bhadeshia: Mater. Sci. Technol., 5 (1989), 131.

26) C. Wert and C. Zener: J. Appl. Phys., 21 (1950), 5.

27) R. Trivedi: Acta Metall., 18 (1970), 287.

28) C. Zener: Trans. AIME, 167 (1946), 550.

29) J. Fridberg, L.-E. Törndahl and M. Hillert: Jernkontorets Ann., 153 (1969), 263

30) J. M. Darbyshire and J. Barford: Central Electricity Research Laboratory Report, RD/L/R 1408, (1966).

31) H. B. Aaron and H. I. Aaronson: Acta Metall., 18 (1988), 699. 